\title{
IMPLEMENTASI KEBIJAKAN INPASSING JABATAN GURU BUKAN PNS SMP SWASTA KABUPATEN KENDAL
}

\author{
Sutadi ${ }^{1}$
}

\begin{abstract}
One of the government's efforts in improving the quality of teachers is to implement the policy of determining the inpassing of functional positions of non-civil servant teachers and credit figures. According to Permendikbud number 47 of 2007 renewed Permendiknas no. 22 Year 2010 Inpassing Non Civil Servant Teachers (GBPNS) is the process of adjusting the rank of Non-Civil Servant Teachers to the rank of Master Civil Servant. Permendikbud Number 28 of 2014 renewed Permendikbud Number 12 of 2016 on the granting of equal positions and rank for non-civil servant teachers. Implementation of Inpassing Teacher Program Policy Non PNS SMP Kendal private sector concluded: a) All teachers who are certified educators are able to make a proposal document inpassing the positions of teachers instead of civil servants; b) All teachers remain a certified foundation of educators proposing SK inpassing; c) Only 10\% of the proposals can be issued inpassing decree from the Ministry of Education and Culture. The results of research on the factors that inhibit the implementation of policy inpassing the position of junior high school teachers rather than civil servants in Kendal District: a) Communication Factor, the absence of communication between teacher or school with Ministry of Education and Culture related to proposal of inpassing of non-civil servant teacher position become one of the point that hinder the implementation of program; $b$ ) Factors Resources, lack of human resources administrative staff in private schools in this case associated with the fulfillment of standards of educational personnel to be one obstacle policy implementation; c) Disposition Factors, Understanding teachers, administrative staff, principals and officials of the District Education and Culture District of Kendal is a good factor driving the implementation of inpassing program. The conclusion of the policy implementation of inpassing of junior high school teachers rather than civil servants in private schools in Kendal District has not been successful.
\end{abstract}

Keywords: implementation, inpassing, teacher not civil servant

\section{PENDAHULUAN}

Masalah yang harus diatasi oleh pemerintah adalah masalah publik yaitu nilai, kebutuhan atau peluang yang tak terwujudkan. Meskipun masalah tersebut dapat diidentifikasi tapi hanya mungkin dicapai lewat tindakan publik yaitu melalui kebijakan publik (Dunn dalam Nugroho, 2008 : 58). Karakteristik masalah publik yang harus diatasi

\footnotetext{
${ }^{1}$ Mahasiswa Prodi S2 Ilmu Administrasi, Departemen Adm Publik, Universitas Diponegoro
} 
selain bersifat interdependensi (berketergantungan) juga bersifat dinamis, sehingga pemecahan masalahnya memerlukan pendekatan holistik (holistic approach) yaitu pendekatan yang memandang masalah sebagai kegiatan dari keseluruhan yang tidak dapat dipisahkan atau diukur secara terpisah dari yang faktor lainnya. Untuk itu, diperlukan kebijakan publik sebagai instrumen pencapaian tujuan pemerintah.

Pendidikan merupakan salah satu pilar terpenting dalam meningkatkan kualitas manusia. Kinerja pendidikan sebagai alat ukur keberhasilan merupakan gabungan Angka Partisipasi Kasar (APK) jenjang pendidikan dasar sampai dengan pendidikan tinggi. Angka melek aksara digunakan sebagai variabel dalam menghitung Indeks Pembangunan Manusia (IPM) bersama-sama dengan variabel kesehatan dan ekonomi. Oleh karena itu, pembangunan pendidikan nasional harus mampu menjamin pemerataan kesempatan pendidikan, peningkatan mutu serta relevansi dan efisiensi manajemen pendidikan untuk menghadapi tantangan sesuai dengan tuntutan perubahan kehidupan lokal, nasional, dan global.

Pendidikan adalah salah satu urusan pemerintahan wajib yang berkaiatan dengan pelayanan dasar. Salah satu permasalalam renstra Dinas Pendidikan dan Kebudayaan Kabupaten Kendal adalah masih rendahnya kualitas pendidik khususnya di jenjang PAUD dan Sekolah Dasar. Hal tersebut dapat dilihat dari masih rendahnya persentase pendidik dengan kualifikasi sarjana (S-1) atau Diploma empat (D-IV) untuk pendidik PAUD 46,36\% dan Sekolah Dasar sederajat sebesar 84\%. sedangkan untuk jenjang Sekolah Menengah Pertama sederajat sudah mampu mencapai 91,4\%. ( Baperlitbang, Dokumen Perencanaan Kabupaten Kendal 2015-2020)

Dari kajian terhadap Renstra Dinas Pendidikan dan Kebudayaan berkaitan masih minimnya kesejahteraan pendidik bukan PNS menjadi salah satu isu yang akan ditangani dalam pengelolaan kebijakan peningkatan kualitas pendidikan. Melalui perbaikan kesejahteraan tenaga pendidik diharapkan dapat ditingkatkan kualitas pendidikan karena dengan kesejahteraan yang cukup maka mereka akan lebih fokus dalam menjalankan tugas dan tanggung jawabnya sebagai pendidik. Salah satu upaya pemerintah dalam meningkatkan mutu guru adalah dengan melaksanakan kebijakan penetapan inpassing jabatan fungsional guru bukan PNS dan angka kreditnya. Menurut Permendikbud nomor 47 Tahun 2007 Inpassing Guru Bukan Pegawai Negeri Sipil (GBPNS) adalah proses penyesuaian kepangkatan Guru Bukan Pegawai Negeri Sipil dengan kepangkatan Guru 
Pegawai Negeri Sipil. Inpassing Jabatan Fungsional guru bukan PNS dan Angka Kreditnya ditetapkan berdasarkan dua hal, yaitu kualifikasi akademik dan masa kerja yang dihitung mulai dari pengangkatan atau penugasan sebagai pada satuan pendidikan. Pelaksanaannya dimuat dalam peraturan Permendiknas Nomor 47 Tahun 2007 tentang Inpassing Guru Bukan PNS kemudian direvisi dengan Permendiknas Nomor 22 Tahun 2010. Dalam perkembangan muncul kebijakan Peraturan Menteri Pendidikan dan Kebudayaan Nomor 69 Tahun 2012 tentang Perubahan atas Peraturan Menteri Pendidikan dan Kebudayaan Nomor 1 Tahun 2012 tentang Organisasi dan tata Kerja Kementerian Pendidikan dan Kebudayaan serta Peraturan Menteri Negara Pendayagunaan Aparatur Negara dan Reformasi Birokrasi Nomor 16 Tahun 2009 tentang Jabatan Fungsional Guru dan Angka Kreditnya. Munculnya hal ini menyebabkan adanya perubahan kebijakan inpassing yang diwujudkan dalam Peraturan Menteri Pendidikan dan Kebudayaan Republik Indonesia Nomor 28 Tahun 2014 tentang Pemberian kesetaraan jabatan dan pangkat bagi guru bukan pegawai negeri sipil. Guna menyempurnakan upaya pemberian kesetaraan guru bukan PNS terbit Peraturan Menteri Pendidikan dan Kebudayaan Republik Indonesia Nomor 12 Tahun 2016 tentang perubahan atas Peraturan Menteri Pendidikan dan Kebudayaan nomor 28 Tahun 2014. Berdasarkan Permendikbud nomor 12 Tahun 2016 prosedur tersebut dapat digambarkan sebagai berikut: 
Gambar I. 1: Skema pengusulan inpassing

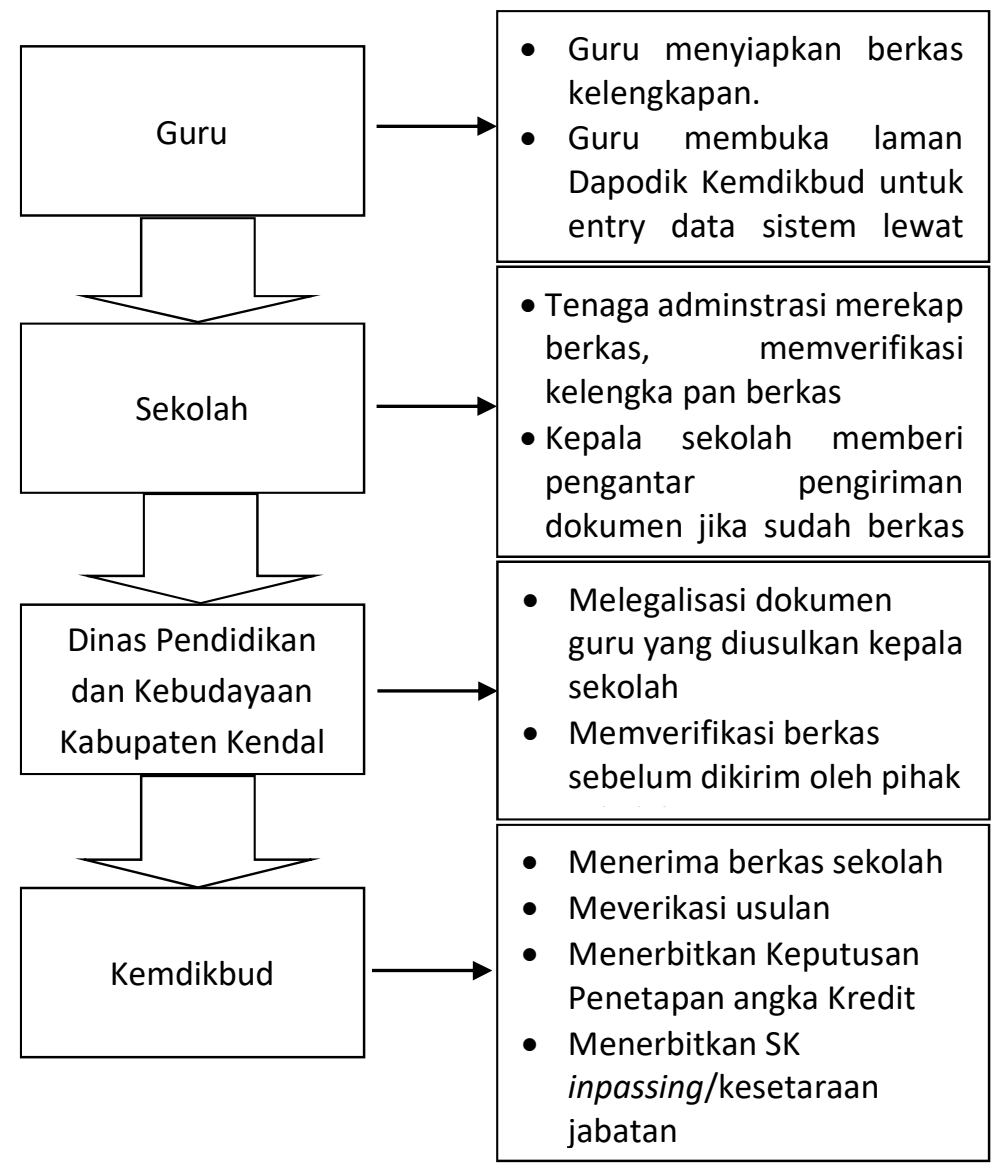

Dari persyaratan dan prosedur pengusulan inpassing ( penyetaraan ) jabatan guru ini akan dikaji sejauh mana implementasi kebijakan ini khususnya bagi guru bukan PNS di SMP swasta Kabupaten Kendal

Sekalipun manfaatnya sangat besar dalam meningkatkan kesejahteraan guru bukan PNS namun dalam prateknya kebijakan inpassing ini belum sepenuhnya dapat dinikmati oleh semua guru bukan PNS. Data Guru SMP Swasta Kabupaten Kendal tahun 2017. Data menunjukan 60,3 \% guru SMP swasta Kabupaten Kendal bersertifikat pendidik belum mendapat pengakuan kesetaraan atas jabatan mereka (inpassing). Pengakuan jabatan sangat penting karena berpengaruh langsung pada tunjangan profesi yang diterima. Berdasarkan identifikasi masalah yang tersebut di atas, maka permasalahan penelitian ini dapat dirumuskan sebagai berikut :

a. Bagaimana implementasi kebijakan Inpassing jabatan guru bukan PNS di SMP Swasta Kabupaten Kendal 
b. Apa faktor yang mendorong dan menghambat implementasi kebijakan Inpassing jabatan guru bukan PNS di SMP Swasta Kabupaten Kendal.

\section{Kajian Teori}

Dari kajian penelitian-penelitian di atas ditemukan motivasi kerja akan meningkat jika mereka sejahtera, oleh karena itu penelitian berkait upaya mengetahui implementasi kebijakan inpassing jabatan guru SMP bukan PNS menjadi relevan diteliti karena akan berdampak dengan upaya perbaikan kesejahteraan guru khususnya guru SMP bukan PNS yang sudah menerima tunjangan profesi.

Makna dari pengertian kebijakan di atas adalah kebijakan publik mengacu ada tindakan pemerintah yang benar-benar dilakukan berdasarkan peraturan yang bersifat memaksa setiap pihak yang tercakup dalam lingkungan kebijakan tersebut. Dalam kajian ini dapat dirumuskan makna kebijakan publik adalah:

a. Segala sesuatu yang dikerjakan dan yang tidak dikerjakan oleh Pemerintah.

b. Kebijakan yang mengatur kehidupan bersama atau kehidupan publik, bukan kehidupan perorangan atau golongan. Kebijakan publik mengatur semua yang ada didomain lembaga administrator publik.

c. Kebijakan yang nilai manfaatnya harus senantiasa ditujukan untuk kepentingan masyarakat.

Peneliti sependapat dengan Thomas Dye, M Irfan Islamy, dan Warella yang menyatakan bahwa kebijakan publik meliputi apa yang dilakukan dan apa yang tidak dilakukan oleh pemerintah. Peneliti berpendapat demikian karena menurut peneliti, apa yang tidak dilakukan oleh pemerintah telah melalui pemikiran dan proses yang panjang untuk menentukan apakah tindakan tersebut akan dilakukan ataupun tidak.

Implementasi kebijakan berfungsi membentuk suatu hubungan yang memungkinkan tujuan ataupun sasaran kebijakan publik diwujudkan sebagai "outcome" (hasil akhir) kegiatan yang dilakukan pemerintah. Solichin (2001: 179) memandang implementasi kebijakan sebagai suatu proses tindakan administrasi dan politik. Keseluruhan proses implementasi kebijakan dapat dievaluasi dengan cara mengukur atau membandingkan antara hasil akhir dari program-program tersebut dengan tujuan kebijakan.

Untuk memperoleh pemahaman yang baik mengenai implementasi kebijakan, Sri Suwitri (2008: 80) menyatakan bahwa hendaknya kita tidak hanya memahami badan 
administratif yang bertanggung jawab terhadap kebijakan/program berikut pelaksanaannya terhadap kelompok-kelompok sasaran, melainkan juga berbagai kekuatan sosial, politik, ekonomi yang secara langsung ataupun tidak langsung mempengaruhi semua pihak yang terlibat, serta dampak yang muncul dari implementasi kebijakan tersebut. Sejalan dengan hal tersebut di atas, Mazmanian dan Sabatier, dalam Solichin Abdul Wahab (2001; 65), memaknai implementasi sebagai usaha untuk memahami apa yang senyatanya terjadi sesudah suatu program diberlakukan atau dirumuskan, yakni peristiwa dan kegiatan yang terjadi setelah proses pengesahan/legislasi kebijakan publik, baik itu menyangkut usaha-usaha untuk mengadministrasikannya maupun usaha-usaha untuk memberikan dampak tertentu pada masyarakat ataupun peristiwa-peristiwa.

Menurut Patton dan Sawicki dalam Tangkilisan (2003) bahwa implementasi berkaitan dengan berbagai kegiatan yang diarahkan untuk merealisasikan program, dimana pada posisi ini eksekutif mengatur cara untuk mengorganisir, menginterpretasikan dan menerapkan kebijakan yang telah diseleksi. Sehingga dengan mengorganisir, seorang eksekutif mampu mengatur secara efektif dan efisien sumber daya, unit-unit dan teknik yang dapat mendukung pelaksanaan program, serta melakukan interpretasi terhadap perencanaan yang telah dibuat, dan petunjuk yang dapat diikuti dengan mudah bagi realisasi program yang dilaksanakan.

Keberhasilan implementasi kebijakan akan ditentukan olah banyak variabel atau faktor dan masing masing. Dari beberapa model implementasi yang akan menjadi kajian dalam penelitian ini adalah Model implementasi George C Edwards III. Model implementasi kebijakan menurut pandangan Edwards III (1980), dipengaruhi empat variabel, yakni; (1) komunikasi, (2) sumberdaya, (3) disposisi dan (4) struktur birokrasi. Faktor yang mempengaruhi implementasi yang akan digunakan adalah model implementasi George C. Edwards III tetapi karena keterbatasan peneliti maka peneliti akan mengkaji pada 3 faktor yaitu komunikasi, sumber daya dan disposisi atas kajian kebijakan inpassing (penyetaraan) jabatan guru bukan PNS di SMP Swasta di Kabupaten Kendal.

\section{Kebijakan Inpassing Jabatan Guru bukan PNS}

Inpassing adalah proses penyetaraan kepangkatan, golongan, dan jabatan fungsional Guru Bukan PNS (GBPNS) dengan kepangkatan, golongan, dan jabatan guru 
PNS dengan tujuan untuk tertib administrasi, pemetaan guru dan kepastian pemberian tunjangan yang menjadi hak mereka. Dalam permendikbud Nomor 12 Tahun 2016 sebagai peraturan lanjutan dari Permendiknas nomor 47 Tahun 2007 diatur bagaimana proses Inpassing/penyetaraan jabatan guru bukan PNS.

Dari kajian dokumen Permendikbud Nomor 12 Tahun 2016 fenomena pengamatan keberhasilan implementasi kebijakan inpassing jabatan guru SMP bukan PNS pada SMP Swasta di Kabupaten Kendal yang akan diamati antara lain:

a. Kemampuan guru menyusun dokumen pengusulan inpassing

b. Jumlah guru yang mengajukan inpassing

c. Jumlah guru yang mendapatkan SK inpassing

Disamping itu kajian atas faktor-faktor yang mempengaruhi implementasi kebijakan inpassing jabatan guru SMP bukan PNS di Kabupaten Kendal akan menjadi bagian dari penelitiaan ini.

Penelitian ini merupakan penelitian kualitatif dengan metode deskripif. Kirk dan Miller (Moleong, 2011:3), mendifinisikan bahwa: "Penelitian kualitatif adalah tradisi tertentu dalam ilmu pengetahuan sosial yang secara fundamental bergantung pada pengamatan manusia dalam kawasan sendiri dan berhubungan dengan orang-orang tertentu dalam bahasa dan peristilahan.

Karena dalam penelitian ini digunakan metode deskriptif yang bersifat eksploratif, metode ini dimaksudkan untuk menggambarkan keadaan atau status fenomena, yang dalam hal ini penelitian hanya ingin mengetahui hal-hal yang berhubungan dengan keadaan sesuatu, menurut Bogdan dan Taylor dalam Moleong (2011:4). Metodelogi kualitatif sebagai prosedur penelitian yang menghasilkan data deskriptif berupa kata-kata tertulis atau lisan dari dari orang-orang dan perilaku yang dapat diamati. Metode kualitatif dapat digunakan untuk mengungkapkan dan memahami sesuatu dibalik fenomena yang sedikitpun belum diketahui.

Menurut Sugiyono (2010:6), penelitian deskriptif adalah "penelitian yang dilakukan terhadap variable mandiri, yaitu tanpa membuat perbandingan atau menghubungkan dengan variable lain" Penelitian kualitatif lebih menghendaki ke arah penyusunan teori subtantif yang berasal dari data. Analisis lebih merupakan pembentukan abstraksi berdasarkan bagian-bagian yang telah dikumpulkan kemudian dikelompokkan. 
Metode penelitian kualitatif menunjukkan kepada prosedur penelitian yang menghasilkan data deskriptif.

Fokus penelitian ini mendiskripsikan Implementasi kebijakan Inpassing Jabatan Guru Bukan PNS serta mengetahui faktor faktor yang mendorong dan menghambat proses inpassing jabatan guru bukan PNS di SMP Swasta Kabupaten Kendal. Lokasi penelitian adalah SMP swasta se Kabupaten Kendal. Dari semua sekolah swasta yang ada di Kabupaten Kendal peneliti mengambil 3 sekolah untuk diamati. Karena keterbatasan waktu, tenaga dan biaya maka peneliti mengambil 3 sekolah dengan 3 yayasan yang berbeda antara lain :

a. PGRI 12 Pageruyung Kendal dibawah yayasan PGRI

b. SMP Muhammadiyah 1 Weleri Kendal dibawah yayasan Pendidikan Dasar dan Menengah Muhammadiyah

c. SMP Islam Terpadu Robbani Kendal dibawah yayasan pendidikan Lembaga Pendidikan Islam Terpadu.

Fenomena yang akan diteliti guna menjawab permasalahan dalam penelitian ini, antara lain :

1. Implementasi permendikbud Nomor 12 Tahun 2016 antara lain:

a. Kemampuan guru menyusun dokumen pengusulan inpassing

b. Jumlah guru yang mengajukan inpassing

c. Jumlah guru yang mendapatkan Surat keputusan inpassing

2. Faktor faktor yang mempengaruhi implementasi kebijakan.

a. Komunikasi, hal ini dapat dilihat dari :

1)Penggunaan media komunikasi

1) Frekuensi penyampaian program

2) Konsistensi penyampaian

3) Bahasa yang digunakan

4) Pemahaman kelompok sasaran kebijakan secara tepat

b. Sumber daya meliputi:

1) Kemampuan sumber daya pelaksana

2) Ketercukupan sumber dana

3) Ketercukupan waktu

c. Disposisi/sikap pelaksana, dilihat dari : 
1) Kemauan pelaksana

2) Komitmen pelaksana

3) Kepatuhan pelaksana

4) Pemahaman pelaksana

Sumber data dalam penelitian ini meliputi : tempat (place), orang/narasumber (person) dan aktifitas (process). Sumber data dipilih melalui pertimbangan untuk menentukan informan untuk wawancara dan dokumen sumber pencermatan pelaksanaan program Inpassing Jabatan guru bukan PNS SMP swasta. Penelitian ini juga akan menggunakan teknik snowballing sampling untuk menggali lebih dalam data dari beberapa orang yang diperoleh dari key informan.

Dalam penelitian ini data yang digunakan adalah data primer dan data sekunder. Teknik pengumpulan data yang di gunakan dalam penelitian ini adalah:

1. Interview/wawancara

2. Dokumentasi

Analisis data, menurut Patton (Moleong, 2011:280), adalah proses mengatur urutan data, mengorganisasikannya ke dalam suatu pola, kategori, dan satuan uraian dasar, yaitu memberikan arti yang signifikan terhadap hasil analisis. Terdapat banyak cara dalam melakukan analisis data, Creswell (2005: 232-235) mengungkapkan beberapa tahap yang harus dilakukan dalam mempersiapkan dan menganalisis data dalam penelitian kualitatif, yaitu:

a. mengumpulkan data ke dalam bentuk file

b. menulis hasil wawancara

c. menganalisa dan mengkodekan hasil wawancara dan data lainnya.

\section{PEMBAHASAN}

\section{Implementasi Kebijakan Program Inpassing Guru Bukan PNS SMP swasta Kabupaten Kendal}

Pendidikan merupakan salah satu pilar penyangga peningkatan kualitas manusia suatu bangsa. Pembangunan pendidikan nasional telah diselenggarakan dengan mempertimbangkan kesepakatan-kesepakatan internasional dan regional. Pendidikan diselenggarakan dengan mempertimbangkan kondisi sosial ekonomi masyarakat, sematamata untuk menciptakan keadilan sosial dalam usaha peningkatan kualitas manusia 
masyarakat suatu bangsa. Ada 3 fenomena yang menjadi pengamatan dalam penelitian ini antara lain:

1. Kemampuan guru menyusun dokumen pengusulan inpassing

2. Jumlah guru yang mengajukan inpassing

3. Jumlah guru yang mendapatkan SK inpassing

Hasil wawancara di lapangan ditemukan beberapa hal terkait implementasi pengusulan inpassing jabatan guru SMP Bukan PNS. Dari kajian penelitian pada prinsipnya usulan inpassing dari guru ke kementerian tidak mengalami kesulitan. Guru mampu menyusun dokumen usulan berdasarkan juknis, karena ada dukungan dari yayasan dan dinas pendidikan. Berdasarkan penjelasan dan kajian atas wawancara dengan guru, kepala sekolah dan tenaga adminitrasi maupun pejabat dinas terkait kemampuan guru menyusun dokumen usul inpassing tidak ada kesulitan bagi semua guru SMP bukan PNS yang telah menjadi guru tetap yayasan.

Dari hasil penelitian dokumen administrasi tata usaha dilaporkan bahwa sampai saat ini baru terbit 2 surat keputusan Inpassing guru SMP Muhammadiyah 1 Weleri Kendal atas nama Yogi Pratiwi Kusumaningrum usulan surat keputusan inpassing Januari 2017 dan Mur Sutami,S.Pd usulan Desember 2016. Sedangkan di sekolah lain yang kami teliti yaitu di SMP IT Robbani Kendal dan SMP PGRI 12 Pageruyung Kendal tidak ada data terbitnya surat keputusan inpassing.

Dari hasil kajian dokumen dan wawancara terhadap pelaksana kebijakan dan penerima kebijakan khususnya dalam impelementasi kebijakan inpassing jabatan guru SMP bukan PNS di Kabupaten Kendal sejak terbit Permendikbud nomor 47 Tahun 2008 sampai dengan terbitnya Permendikbud nomor 12 Tahun 20016 tentang inpassing/penyetaraan atas jabatan guru bukan PNS dalam pelaksanaan hasilnya tidak optimal. Sehingga dalam kaitan ini pembuat kebijakan perlu melakukan kajian lebih lanjut agar kebijakan ini bisa lebih baik hasil implementasinya di lapangan.

\section{Hasil penelitian atas faktor-faktor yang menghambat implementasi kebijakan inpassing jabatan guru SMP bukan PNS di Kabupaten Kendal \\ Terkait tiga faktor yang mempengaruhi implementasi kebijakan inpassing jabatan guru SMP bukan PNS di Kabupaten Kendal.}




\section{Faktor Komunikasi}

Komunikasi merupakan faktor yang penting dalam implementasi. Komunikasi adalah hubungan kontak antar dan antara manusia, baik individu maupun kelompok, untuk menyampaikan pesan antar pelaku proses komunikasi. Proses komunikasi yang dijalankan harus dapat dipahami oleh antar pelaku proses komunikasi tersebut sehingga mereka dapat memahami pesan yang disampaikan. Komunikasi juga berfungsi memperkuat motivasi dengan menjelaskan kepada pelaku komunikasi yang lain tentang apa yang harus dikerjakan untuk memperbaiki kinerjanya.

Komunikasi dikatakan efektif bila orang berhasil menyampaikan apa yang dimaksudkannya. Sebenarnya, ini hanya salah satu ukuran bagi efektivitas komunikasi. Secara umum, komunikasi dinilai efektif bila rangsangan yang disampaikan dan yang dimaksudkan oleh pengirim atau sumber, berkaitan erat dengan rangsangan yang ditangkap dan dipahami oleh penerima (Tubbs, Stewart L \& Sylvia Moss. 2000). Pemahaman atas kebijakan sangat dibutuhkan dalam implementasi kebijakan melalui komunikasi. Kondisi ini belum secara optimal didapatkan dalam kaitan implementasi kebijakan inpassing jabatan guru bukan PNS pada SMP swasta di Kabupaten Kendal. Dari sisi penjelasan program tentang kebijakan, komunikasi program tertolong dengan adanya teknologi. Kurangnya komunikasi terutama antara guru atau sekolah dengan pihak Kementerian Pendidikan dan Kebudayaan terkait hal ini menjadi salah satu titik lemah yang menghambat impelementasi program.

\section{Faktor Sumber daya}

Semua ahli dalam kebijakan publik menkyatakan bahwa sumber daya merupakan faktor yang penting dalam implementasi suatu kebijakan, yakni sumber daya manusia, sumber daya finansial/dana, sumber daya fisik, dan sumber daya waktu. Ada tiga faktor sumber daya yang diamati dalam penelitian implementasi program inpassing di SMP yakni: sumber daya manusia, sumber dana, dan sumber daya waktu.

Secara umum terkait faktor sumber daya untuk masalah sumber daya manusia dan sumber dana menjadi salah satu faktor yang menghambat proses implementasi kebijakan. Kurangnya sumber daya manusia tenaga adminitrasi di sekolah swasta yang dalam hal ini terkait dengan pemenuhan standar tenaga kependidikan menjadi salah satu penghambat implementasi kebijakan. 


\section{Faktor Disposisi}

Disposisi atau sikap pelaksana dalam mengimplementasikan kebijakan berpengaruh terhadap berhasil atau tidaknya implementasi kebijakan ini. Sikap pelaksana diharapkan dapat mendukung program ini sehingga proses implementasi dapat berjalan dengan baik. Edward III (1980) menyatakan bahwa disposition berkenaan dengan kesediaan dari para implementor untuk melaksanakan suatu kebijakan publik. Kecakapan saja tidak mencukupi, tanpa kesediaan dan komitmen untuk melaksanakan kebijakan. Para ahli berpendapat bahwa dalam implementasi program inpassing di SMP swasta se Kabupaten Kendal diperlukan:

1. Kemauan, komitmen, dan kepatuhan dari implementor kebijakan untuk melaksanakan kebijakan dengan baik,

2. Pemahaman yang baik dari implementor kebijakan mengenai isi kebijakan agar dapat melaksanakan kebijakan dengan baik.

Pelaksana inpassing di SMP PGRI 12 Pageruyung Kendal, SMP Muhammadiyah 1 Weleri Kendal, SMP Islam Terpadu Robbani Kendal memiliki komitmen yang besar untuk selalu patuh terhadap segala peraturan yang ada dalam petunjuk teknis inpassing agar program inpassing ini dapat terlaksana dengan baik. Subarsono,A.G. (2005) menambahkan watak dan karakteristik yang dimiliki oleh implementor, seperti komitmen, kejujuran, sifat demokratis sebagai definisi disposisi. Beragamnya pemahaman mensikapi kondisi lingkungan menjadi bagian yang mewarnai beragamnya tingkat kejujuran, komitmen dari implementor.

Pemahaman mereka yang baik terhadap isi kebijakan ini membuat mereka dapat mengimplementasikan program inpassing ini dengan baik seharusnya. Dari kajian 3 faktor yang mempengaruhi implementasi kebijakan ada 2 yang menghambat implementasi, yaitu faktor komunikasi dan sumber daya. Sedangkan faktor disposisi memberikan dorongan implementasi kebijakan inpassing jabatan guru bukan PNS pada SMP swasta Kabupaten Kendal.

Komunikasi informasi atas capaian perkembangan proses inpassing guru yang mengusulkan inpassing jabatan guru bukan PNS dengan Kementerian Pendidikan dan Kebudayaan tidak berjalan dengan baik. Sehingga perlu dilakukan upaya pembenahan komunikasi Dinas Pendidikan dan Kebudayaan dengan Kementerian Pendidikan dan Kebudayaan di Jakarta. Mekanisme pengecekan atas tidak terbitnya surat keputusan 
inpassing perlu dibuka aksesnya. Jika selama ini guru yang memenuhi syarat mendapatkan surat keputusan inpassing sedangkan guru yang tidak mendapatkan SK inpassing perlu penjelasan apakah dokumen yang disusun kurang lengkap atau dokumen salah.

Faktor lain yang mempengaruhi implementasi dalam teori Edward III yaitu struktur birokrasi, dalam penelitian ini belum dilakukan kajian mendalam karena keterbatasan peneliti. Kajian atas kegagalan implementasi kebijakan inpassing juga diduga karena faktor keterbatasan anggaran. Jika program ini berhasil maka anggaran pemerintah untuk pembiayaan akan meningkat. Hal ini menjadi bahan kajian penelitian lebih lanjut bagi peneliti lain

\section{PENUTUP}

Pelaksana kebijakan merupakan pihak-pihak yang menjalankan kebijakan yang terdiri dari penentuan tujuan dan sasaran organisasional, analisis serta perumusan kebijakan dan strategi organisasi, pengambilan keputusan, perencanaan, penyusunan program, pengorganisasian, penggerakkan manusia, pelaksanaan operasional, pengawasan serta penilaian. Keberhasilan kebijakan publik tidak lepas dari keberhasilan implementasi kebijakan di lapangan.

Berdasarkan pada kajian atas petunjuk teknis pelaksanaan Peraturan Menteri Pendidikan dan Kebudayaan Nomor 12 Tahun 2016 tentang Penyetaraan jabatan (inpassing) guru bukan PNS dan kajian faktor yang mempengaruhi implementasi kebijakan yang di kembangkan oleh George C. Edwards III maka hasil analisis data penelitian terhadap fenomena penelitian, dapat disimpulkan hal-hal sebagai berikut:

1. Untuk Implementasi kebijakan Program Inpassing Guru Bukan PNS SMP swasta Kabupaten Kendal diperoleh kesimpulan :

a. Semua guru yang bersertifikat pendidik mampu membuat dokumen usulan inpassing jabatan guru bukan PNS. Pengusulan SK Inpassing jabatan guru bukan PNS dilakukan semua sekolah swasta sepanjang memenuhi persyaratan Permendikbud Nomor 12 tahun 2016. Dinas Pendidikan dan Kebudayaan Kabupaten Kendal membantu menfasilitasi antara lain dengan melegalisir usulan guru, melakukan pengarsipan, melakukan bimbingan ke yayasan. 
b. Semua guru tetap yayasan yang bersertifikat pendidik mengajukan usulan SK inpassing

c. Penerbitan surat keputusan inpassing dari Kementerian Pendidikan dan Kebudayaan baru $10 \%$ dari usulan yang diajukan. Hal ini karena hanya ada 2 guru yang mendapat surat keputusan dari 20 usulan.

2. Hasil penelitian atas faktor-faktor yang mendorong dan menghambat implementasi kebijakan inpassing jabatan guru SMP bukan PNS di Kabupaten Kendal Merujuk pada teori yang dikemukakan George C. Edwards III terdapat tiga aspek yang dikaji dalam penelitian ini. Ketiga aspek faktor-faktor yang mempengaruhi implementasi kebijakan.

a. Faktor Komunikasi. Komunikasi guru, pihak sekolah, Dinas Pendidikan dan Kebudayaan Kabupaten Kendal dengan pihak Kementerian Pendidikan dan Kebudayaan terkait usulan inpassing sangat lemah. Kelemahan komunikai ini ditunjukan dengan tidak adanya jalur komunikasi guru dan sekolah ke Kemdikbud. Guru memperoleh informasi hanya hasil Surat Keputusan sementara komunikasi atas alasan belum terbitnya surat keputusan inpassing guru tidak ada. Laman Kementerian Pendidikan dan Kebudayaan tentang inpassing hanya menampilkan infomasi penerbitan surat keputusan tidak ada informasi terhadap alasan belum terbitnya surat keputusan. Faktor komunikasi menjadi penghambat dalam implementasi kebijakan inpassing jabatan guru bukan PNS SMP swasta Kabupaten Kendal.

b. Faktor Sumber daya. Secara umum terkait faktor sumber daya untuk masalah sumber daya manusia dan sumber dana menjadi salah satu faktor yang menghambat proses implementasi kebijakan. Kurangnya sumber daya manusia tenaga adminitrasi di sekolah swasta yang dalam hal ini terkait dengan pemenuhan standar tenaga kependidikan menjadi salah satu penghambat implementasi kebijakan. Faktor sumber daya menjadi penghambat dalam implementasi kebijakan inpassing jabatan guru bukan PNS SMP swasta Kabupaten Kendal. Pendanaan atas program inpassing di sekolah dibebankan pada sekolah dan guru, tidak ada dana yang dialokasikan secara khusus dari 
Pemerintah Daerah maupun pusat untuk melaksanakan inpassing jabatan guru bukan PNS pada SMP Swasta di Kabupaten Kendal

c. Faktor Disposisi, pemahaman pelaksana kebijakan ditingkat Dinas Pendidikan dan Kebudayaan Kabupaten Kendal, Kepala sekolah, tenaga administrasi dan guru tetap yayasan yang baik terhadap isi kebijakan seharusnya dapat mendorong keberhasila implementasi program inpassing jabatan guru bukan PNS. Faktor disposisi menjadi pendorong dalam implementasi kebijakan inpassing jabatan guru bukan PNS SMP swasta Kabupaten Kendal

Dari kajian 3 faktor yang mempengaruhi implementasi kebijakan ada 2 yang tidak memberikan dukungan positif, yaitu faktor komunikasi dan sumber daya. Data hasil penelitian seluruh guru yang mengajukan inpassing jabatan guru SMP bukan PNS pada SMP Swasta Kabupaten Kendal hanya $10 \%$ yang berhasil memperoleh surat keputusan dari Kementerian Pendidikan dan Kebudayaan . Sehingga inpassing jabatan guru SMP bukan PNS pada SMP Swasta Kabupaten Kendal tidak berhasil. Kesimpulan diharapkan dapat menjadi gambaran bahwa implementasi kebijakan inpassing guru SMP bukan PNS pada sekolah swasta di Kabupaten Kendal harus dibenahi.

\section{DAFTAR PUSTAKA}

Creswell. John W., 2005, Educational Research: Planning, Conducting, and Evaluating Quantitative and Qualitative Research, Pearson Education, Inc., New Jersey.

Dunn. N., 1994, Public Policy Analysis: An Introduction, Englewood Cliffs, PrenticeHall International, New Jersey.

Edwards. George C. III, dan Ira Sharkansky, 1978, The policy Predicament, W.H. Freeman and Company, San Fransisco.

Edward III, George C, 1980, Implementing Public Policy, Washington: Congressional Quarterly Inc.

Effendy, Onong Uchjana, 1994, Komunikasi Teori dan Praktek, Remaja Rosdakarya, Bandung.

Ekowati, Mas Roro Lilik, 2005, Perencanaan, Implementasi dan Evaluasi Kebijakan atau Program, Edisi Revisi, PT Rosdakarya, Bandung. 
Erni Sulastri, 2012, Pengaruh sertifikasi guru dan motivasi kerja terhadap kinerja guru SMA Negeri 1 Jjuwana Kabupaten Pati. Under Graduates thesis, Universitas Negeri Semarang.

Farida Ulfah , Pengaruh sertifikasi guru terhadap kinerjaguru ekonomi akuntansi SMA dan SMK se Kabupaten Jepara, Universitas Negeri Semarang, 2009

Habibah , 2014, Dampak tunjangan sertifikasi terhadap gaya hidup Konsumtif guru (studi kasus: Yayasan sa'adatuddarain, Mampang-Jakarta selatan), UIN Syarif Hidayatullah

Handoko, T, Hani, 2003, Manajemen, Edisi 2, BPFE, Yogyakarta

Laswell. Harold D. dan Abraham Kaplan, 1970, Power and Society, Yale University Press, New Haven.

Mulyasa. (2011). Menjadi Guru Profesional (Menciptakan Pembelajaran Kreatif dan Menyenangkan. Bandung: Rosdakarya.

Moleong, Lexy J.,2011. Metodologi penelitian kualitatif . Bandung: Remaja Rosdakarya M Irfan Islamy, 2001, Prinsip Prinsip Perumusan Kebijakan Negara, cetakan ke 7, Bumi

Aksara

Rakhmad, J, 1993, Psikologi Komunikasi, PT. Remaja Rosdakarya, Bandung.

Robbins. Stephen P., 2007, Perilaku Organisasi, PT. Indeks, Jakarta.

Ruben, Brent D,Steward, Lea P, 2005, Communication and Human Behaviour,USA:

Alyn and Bacon

Simamora. Henry, 2006, Manajemen Sumber Daya Manusia, PT. Indeks, Yogyakarta.

Subarsono, A. G., 2005, Analisis Kebijakan Publik, Pustaka Pelajar, Yogyakarta.

Suwitri. Sri, 2008, Konsep Dasar Kebijakan Publik, Badan Penerbit Universitas Diponegoro, Semarang.

Sugiyono. 2010. Metode Penelitian Pendidikan Pendekatan Kuantitatif, Kualitatif dan $R \& D$. Bandung: Alfabeta Bandung

Siswandari dan Susilaningsih , 2013, Dampak sertifikasi guru terhadap peningkatan kualitas pembelajaran peserta didik ( The effect of teacher sertification toward the improvement of Students' learning quality ) Universitas Sebelas Maret

Subagyo Brotosejati,Jurnal Managemen Pendidikan, Volume 1 Nomor 2, Agustus 2012, Universitas Bangun Nusantara Sukoharjo. 
Tubbs, Stewart L \& Sylvia Moss. 2000. Human Communication (Prinsip Prinsip dasar). Bandung : PT Remaja Rosdakarya

Tangkilisan, Nogis, Hegel, 2003, Implementasi Kebijakan Public: Transformasi Pikiran George Edwards, IP, Yogyakarta.

Thomas Dye, 1978, Undestanding Public Polycy, New Jersey: Prentice Hall, Ins

Tilaar. H.A.R \& Riant Nugroho, 2008, Kebijakan Pendidikan: Pengantar untuk Memahami Kebijakan Pendidikan dan Kebijakan Pendidikan sebagai Kebijakan Publik, Pustaka Pelajar, Yogyakarta.

Wahab.Solichin Abdul, 2001, Analisis Kebijaksanaan Dari Formulasi Ke Implementasi Kebijaksanaan Negara, PT Bumi Aksara, Jakarta Warella, Y., 2002, Kebijakan Publik, MAP UNDIP, Semarang.

Wibawa, Samodra, 1994, Evaluasi Kebijakan Publik, Ed. 1 PT. Raja Grafindo Persada, Jakarta.

Widjaja, A.W., 2000, Ilmu Komunikasi, Rineka Cipta, Jakarta

Peraturan rujukan :

Undang-undang No 20 Tahun 2003 tentang sistem PendidikanNasional

Undang-undang Nomor 14 Tahun 2005 tentang Guru dan Dosen

Peraturan Menteri Pendidikan Nasional Nomor 47 Tahun 2007 tentang Inpassing jabatan guru bukan PNS

Peraturan Menteri Pendidikan Nasional Nomor 22 Tahun 2010 tentang Perubahan atas permendiknas No 47 Tahun 2007

Peraturan Menteri Pendidikan dan Kebudayaan Nomor 69 Tahun 2012 tentang Perubahan atas Peraturan Menteri Pendidikan dan Kebudayaan Nomor 1 Tahun 2012 tentang Organisasi dan Tata Kerja Kementerian Pendidikan dan Kebudayaan

Peraturan Menteri Negara Pendayagunaan Aparatur Negara dan Reformasi Birokrasi Nomor 16 Tahun 2009 tentang Jabatan Fungsional Guru dan Angka Kreditnya. Peraturan Menteri Pendidikan dan Kebudayaan Republik Indonesia

Peraturan Menteri Pendidikan dan Kebudayaan Nomor 28 Tahun 2014 tentang Pemberian kesetaraan jabatan dan pangkat bagi guru bukan pegawai negeri sipil

Peraturan Menteri Pendidikan dan Kebudayaan Republik Indonesia Nomor 12 Tahun 2016 Tentang Perubahan atas Peraturan Menteri Pendidikan dan Kebudayaan nomor 28 Tahun 2014 
Peraturan Bupati Kendal Nomor 74 Tahun 2016 Tentang Kedudukan, Susunan Organisasi, Tugas dan Fungsi, serta Tata Kerja Pada Dinas Pendidikan dan Kebudayaan Kabupaten Kendal

Dokumen Renstra Dinas Pendidikan dan Kebudayaan Kendal 2016

Dokumen RPJMD Baperlitbang Kabupaten Kendal 2015-2020 